\title{
Attribution of Responsibility for Organizational Wrongdoing: A Partial Test of an Integrated Model
}

\author{
Jeannine A. Gailey \\ Department of Sociology and Anthropology, Texas Christian University TCU, P.O. Box 298710, Fort Worth, TX 76129, USA \\ Correspondence should be addressed to Jeannine A. Gailey; j.gailey@tcu.edu
}

Received 7 June 2013; Revised 17 August 2013; Accepted 31 August 2013

Academic Editor: Kevin M. Beaver

Copyright ( 2013 Jeannine A. Gailey. This is an open access article distributed under the Creative Commons Attribution License, which permits unrestricted use, distribution, and reproduction in any medium, provided the original work is properly cited.

\begin{abstract}
The present study is an exploratory examination of the influence of social and organizational features on respondents' attributions of responsibility for wrongdoing within an organization. Respondents read a vignette of organizational wrongdoing that included the manipulation of social features, such as whether the organizational actor was following orders or acting on his volition (social role) and if the actor tried to cover up his actions or not (deed), and organizational features, such as standard operating procedures (SOP) and institutionalized mental schemas. Following the vignette, respondents made attributional judgments to both the individual actor and organization based on a multidimensional measure of responsibility. Results indicated that the actor's role within the organization, his actions or deeds, and organizational SOP significantly impacted how respondents attributed responsibility (on multiple dimensions) to either the individual or organization. Moreover, results indicated that women and men tended to attribute responsibility differently. Recommendations are made to improve future tests of the integrated model.
\end{abstract}

\section{Introduction}

Research on attribution of responsibility (AR) for organizations and their employees has not mustered a great deal of scholarly attention recently, despite the increasing public attention on corporate/organizational wrongdoing. Although there has been more awareness of corporate/organizational wrongdoing, largely due to the subprime mortgage crisis, financial industry scandals, and reports of government abuse of power, there have been few discussions about the accountability for these untoward actions. The purpose of the present paper is twofold: (1) to test variables, based on Gailey and Lee's [1] theoretical model, that are likely to influence people's AR for organizational wrongdoing and (2) to obtain a clearer and more coherent picture of what happens when someone (e.g., a potential juror) is asked to assign responsibility to organizations and their agents, which is necessary to gain a better understanding of how organizations escape culpability.

The study of how people attribute responsibility has its roots in the classical work of Fritz Heider [2]. Heider's focus is largely on general liability for blame or punishment. The two issues that are vital theoretically for determining responsibility in his model are (1) the extent to which the actor intended, or caused, the effect and (2) the extent to which the action was caused by environmental forces or pressures. Heider argues that as responsibility to the environment increases, responsibility to the individual (or actor) will decrease. Shaver [3] extended Heider's work by proposing that responsibility is a multidimensional concept, which includes consideration of causality (did the actor cause the events), the actor's intent and knowledge, and external factors, such as if the actor was coerced and whether the acts indicate moral wrongfulness. Shaver's contribution is especially appealing because it takes into consideration legally relevant aspects of responsibility $[1,4]$.

Heider's [2] contributions to AR inspired a long tradition of research in psychology and social psychology ([5-8]) and also in related fields such as sociology, organizational studies, communications, and criminology. Hamilton, the most prominent sociologist in the AR field, has refined Heider's classic work and contributed significantly to the AR research to date [9-17].

Inspired by Hamilton's work on AR, Gailey and Lee [1] proposed an integrated model of AR for organizational wrongdoing, situated within the sociological, psychological, and organizational studies literature. Their intent was to form 
a cohesive theoretical model [1]. The model is expansive and far from parsimonious, but does offer scholars an interdisciplinary stepping-stone for furthering the literature on AR for organizational wrongdoing. I argue that testing the model can help us better understand how actual people attribute responsibility in cases of organizational wrongdoing.

Combining the research in psychology and sociology on AR seems like a natural fit, but I argue that one of the most important contributions of Gailey and Lee's [1] model is the addition of variables from the organizational studies literature, especially if one is considering how perceivers attribute responsibility to organizational behaviors. The present study incorporates all three disciplines by testing the more stable characteristics of the model from the sociological literature and two newer features from the organization studies literature and employs the multidimensional measure of responsibility from the psychological literature. In order to maintain consistency with previous AR research $[4,18,19]$, respondents read a vignette based on a case from the human radiation experiments and were asked to attribute responsibility to both the individual and government organization involved in the wrongdoing.

\section{Literature Review}

2.1. Roles and Deeds. Hamilton's [9-11] most well-known contribution to AR research is her "roles-and-deeds" model. She conceptualized roles as the actor's hierarchical position within an organization. Deeds are the actor's actions and mental state within which the act occurred. Psychological research since Piaget [20] has tended to view responsibility as a product of a person's deeds, in particular, the consequences of the act and an actor's mental state. Research has shown that more serious consequences typically lead to greater AR. People are held more responsible for their intentional acts, somewhat less responsible for their negligent acts, and least responsible for unintentional, nonnegligent acts that lead to unavoidable accidents [21].

According to Hamilton and Sanders [12-15], social roles are equally important to consider. Hamilton and colleagues have conceptualized roles on two dimensions: vertical and horizontal. Vertically, people relate to one another as superiors, equals, or subordinates. Horizontally, people see others as intimates, acquaintances, or strangers, which she refers to as the solidarity dimension. Most often, superiors are held vicariously responsible for the acts of subordinates. In sanctioning judgments, different roles seem to provide differing criteria in terms of the level of intent necessary for "guilt" $[16,17]$. In other words, it is not just what a person did (i.e., deed), but what the person did given whether he or she is a superior acting in an autonomous role or a subordinate acting in an obedient role (i.e., role) that determines how they will be judged $[1,18,19]$. Hamilton's research shows that respondents take into account the social role of the actor, not just the actions, when attributing responsibility, but that both are important determinants [4].

Based on Hamilton's extensive scholarship and Gailey and Lee's $[18,19]$ theoretical and empirical work, I expect respondents who receive the autonomous role vignette to attribute more responsibility to the individual than respondents who receive the obedient role vignette and respondents who receive the obedient role vignette to attribute more responsibility to the organization than respondents who receive the autonomous role vignette.

Nature of the deed varies in the vignette by manipulating if the individual tries to conceal his actions or provides informed consent to the patient involved in the experiment. Therefore, respondents who receive a vignette where the individual covers up what he has done will attribute more responsibility to the individual than respondents who receive the informed consent vignette. If consent is provided, I expect no significant difference in how respondents attribute responsibility to the individual or organization.

2.2. Institutional Logics. Within the organizations studies literature, scholars have stressed the importance of the inclusion of institutional logics to explain connections between an organizational field and the behavior of actors within the organization [22]. Institutional logics provide the behavioral scripts (SOP) of actors and guide their actions, practices, and cognitive frameworks (mental schemas). Therefore, the examination of institutional logics provides one way to measure the influence of institutions on individual and organizational behavior [22].

Institutional logics prescribe behaviors and decisions for persons in organizational contexts, which is why few organizational agents make decisions based on free will ([23]; see also [24] on "bounded rationality"). They may believe that they are making decisions, but in many cases the institution has provided the SOP and mental schemas to guide behavior and shape what choices are expected ([25, 26]; see also [27] on "premise controls"). According to this perspective, decisions and decision making are best understood in terms of social representations, not rational choices [28]. "Decisions" are constructed after the occurrence as narratives to help participants understand unreflective actions taken by the organization; they are not the cause of these actions. They subsequently influence processes, facilitate new actions, and give meanings to events that occur within the organization.

Decision making is often diffused because actors refer to SOP when confronted with a new situation or do not know how to handle a given situation. Kriesberg ([29]: 1091) states, "Most corporate actions consist simply of subcorporate units following these regularized procedures." Supervisors, even when they are in an autonomous role, are still influenced by institutional logic and do not necessarily act from a position of agency. Institutional logics are an important source of mental schemas on which observers rely to make sense of events, such as organizational wrongdoing [30].

Gailey and Lee [1] aptly note that SOP and mental schemas have important implications for AR because these two variables could determine the extent to which respondents believe that the actor did or did not possess free will, thus affecting AR. Gailey and Lee [1] argue that AR scholars can benefit by explicitly including in their vignettes elements of institutional logics, such as SOP and mental schemas. If respondents believe that actors are behaving according to schemas or routines or are following behavioral scripts 
that are reinforced within the organizational, industrial, or institutional context, then this might affect how audiences attribute responsibility for wrongdoing, regardless of the actor's role or possibly even the nature of the deed.

Based on the above literature, I expect respondents who receive the vignette where it was the SOP for the organization to experiment on people to attribute more responsibility to the organization than respondents who receive the vignette where it was not the SOP to experiment on people. Moreover, respondents who receive the vignette where it was the SOP to experiment on people will attribute responsibility to the individual than respondents who receive the vignette where it was not the SOP to experiment on people.

Respondents who receive vignettes where mental schemas are present, meaning that a sentence was added that stated that the actor did not believe the administration of radiation would be a problem, will attribute more responsibility to the organization than respondents who receive vignettes where mental schemas are not present. In addition, respondents who receive vignettes where the above sentence, mental schemas, was omitted will attribute more responsibility to the individual than respondents who receive vignettes where mental schemas are present.

2.3. Respondent Characteristics. The previous research presents somewhat mixed findings regarding how men and women attribute responsibility. For instance, Landry et al. [31] found that women had a higher degree of ethical sophistication with regard to recognizing the nuances of moral issues presented in vignettes. Women also demonstrated stronger responses with respect to situations involving unfairness, injustice, and moral wrongfulness (see also [32]). Whereas, Krulewitz and Nash [7] found that women attributed greater responsibility to the victim than men, but the respondent's sex did not affect AR for the assailant. Thus, respondents rely, in some circumstances, not only on the deed itself, but also on sex-role stereotypes in AR. Moreover, Sanders and Hamilton [16] found that while women were more likely to advocate that something happens to the wrongdoer than men, they did not significantly differ in their AR. Based on this information, I expect women to attribute more responsibility to both the individual and organization than men.

2.4. Responsibility as a Multidimensional Concept. The present study also contributes to the literature by furthering the conversation regarding the measurement of responsibility. The majority of the AR research $[14,17-19,33]$ has utilized a one-dimensional measure responsibility. For instance, respondents are typically asked how responsible an actor is for an event based on a scale of not at all responsible to completely responsible. Prior to Gailey and Falk [4], scholars had not attempted to measure AR as a multidimensional construct. Gailey and Falk [4] employed Shaver's [3] conceptualization and tested the multidimensionality of responsibility using confirmatory factor analysis in two studies with undergraduate populations. Their findings revealed four dimensions of responsibility, not five as Shaver had originally theorized. The present study borrowed Gailey and Falk's measurement model, which includes a nearly identical vignette and employment of their measurement model.

Considering the influence of Hamilton's work on AR (actor's roles and deeds) and the importance of examining institutional logics (mental schemas and SOPs) for determining organizational behavior, I chose to begin with these variables to test Gailey and Lee's [1] integrated model. In order to establish consistency in the measurement of responsibility, I used Gailey and Falk's [4] operationalization of responsibility as a multidimensional concept and incorporated their vignette to test the reliability and validity of their model and extend Gailey and Lee's [1] theoretical model. This exploratory research is important for furthering our academic understandings of $\mathrm{AR}$, but it is also important on a more practical level because it can enlighten us about which circumstances and characteristics affect perceiver's assignment of responsibility in complicated cases of organizational wrongdoing. Figure 1 includes the variables tested in the present study which were selected from Gailey and Lee's theoretical model.

\section{Method}

3.1. Sample. Data were collected from 228 undergraduate students at a large Midwestern university. The sample consisted of 92 men and 129 women; 7 respondents did not indicate their sex. The average age of participants was 22 and ages ranged from 17 to 53 . Sixty-eight percent of the sample reported that they were Caucasian, 24 percent African American, three percent Asian/Pacific Islander, half a percent Hispanic, and four and a half percent reported other; nine respondents did not report their race. Sixty-one percent were freshmen, 27 percent were sophomores, ten percent were juniors, and two percent were seniors. The average GPA reported by respondents was a 3.08 and GPA ranged from 1.00 to a 4.00. Preliminary analysis indicated that respondent characteristics such as race, GPA, and class rank did not significantly contribute to the model probably because of the homogeneity of the sample. All analysis and descriptive statistics are available from the author upon request.

3.2. Procedures. Ten introductions to sociology classes were randomly selected for data collection at the beginning of the semester. All participants were asked to complete a survey that consisted of a vignette, described below, followed by 28 questions that measured responsibility for both the individual and the organization featured in the vignette. Participants were randomly assigned to receive one of 16 questionnaires. The vignette included four manipulations: roles and deeds, both of which have previously been manipulated in AR research, and two new variables, mental schemas and SOP. The questionnaires were put together randomly to control for order effects. The questions that followed the vignette were exactly the same across surveys and were constructed based on research conducted by Gailey and Falk [4].

3.3. Materials. The content of the vignette was based on thirty oral histories of scientists collected by the Department of 


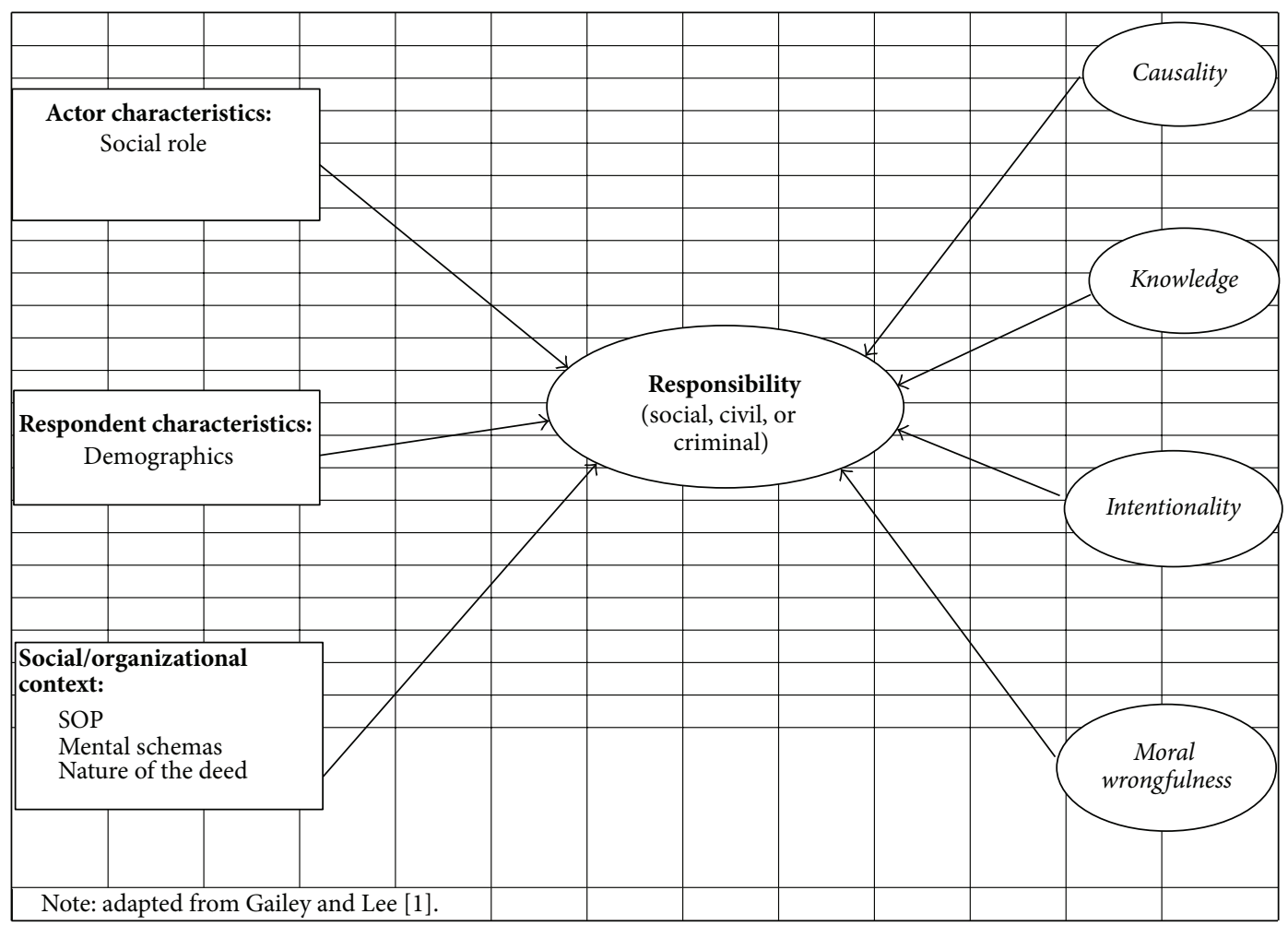

FIGURE 1: Partial integrated model of attribution of responsibility for wrongdoing in organizations.

Energy in 1994-1995 as part of its investigation of the Cold War human radiation experiments. The vignette involves a scientist who injects a patient with a lethal dose of plutonium; it was inspired by one of the radiation experiments and previous research $[4,18,19]$. The name of the actor, Dave, is fictitious (see the Appendix for the vignette and manipulations); however, the fact that some patients who had been diagnosed as terminally ill were injected with plutonium is true, none of the patients consented or even knew they were participating in research, and during this period of time, experiments such as these were typical of the Atomic Energy Commission (AEC). The 28 questions that followed each vignette were extracted from Gailey and Falk's [4] research.

\subsection{Measurement}

3.4.1. Independent Variables. Operational definitions for all of the independent variables are from Gailey and Lee [1, 18, 19] and Gailey and Falk [4] and adapted from Hamilton and colleagues' extensive work on roles and deeds. Role was the first independent variable included in this study and it was divided in two categories: autonomy and obedience. Autonomy is defined as being self-governing. Obedience is defined as being compliant to the restraint or command of authority. Autonomy and obedience were varied based on the actor's role in the experiments. When the actor was in an autonomous role he decided to inject the patient with plutonium, but when the actor was in an obedient role he was ordered by the AEC to inject the patient with plutonium.
Deed was the second independent variable and it was also classified in two categories: cover-up and informed consent. In the cover-up scenario, the patient or the patient's relatives were not given full informed consent (e.g., the actor does not document the injection in the patient's chart). In the informed consent situation, the patient was informed of his/her participation in the research and it was documented in his chart.

The third independent variable was mental schema, which was also divided in two categories: schema present and no schema present. When schema was included in the vignette a sentence was added that stated that the actor did not believe that the administration of radiation would be a problem because the patient was diagnosed as terminally ill. Schema not present simply meant that this sentence was omitted.

The fourth independent variable was standard operating procedures (SOP) and this variable was also divided in to two categories: typical or not typical. When the manipulation involved SOP, participants were informed that the actor knew from past experience that using patients in this manner was typical of AEC-funded research. Not typical simply meant participants were informed that using patients in this manner was not typical of AEC-funded research.

The respondent's sex was also included in the model based on slightly mixed findings in previous research about the impact of respondent's sex. As previously noted, there were 129 women and 92 men; 7 respondents did not indicate their sex and were classified as missing. 
3.4.2. Dependent Variables. The dependent variables were created from previous research (see [4]: 678) and Shaver's [3] theoretical conceptualization of the attribution of blame. Each of the following questions was asked twice, once with the insertion of Dave (individual) and once with the insertion of AEC (organization). Each question was measured on a scale of 0-4 (zero indicating the absence of agreement with the statement and four indicating absolute agreement with the statement); there were 28 questions following the vignette, 14 for the individual actor and 14 for the organization. Coefficient alpha for each subscale is in Table 1. Cronbach's alpha level is only moderate for most of the subscales of the dependent variable. According to McDonald [34] this is not uncommon because one of the limitations of using Cronbach's alpha is that the number of items in the scale affects the alpha level. For example, when there are a small number of items in a scale the alpha level is lower than it is when there are many items in a scale (see also Cronbach [35] for a discussion of the limitations of coefficient alpha).

The causality dimension had four indicators: (1) how responsible is Dave/AEC in the vignette for what happened; (2) was Dave/AEC at fault for what happened; (3) could Dave/AEC have avoided injecting the patient with plutonium; (4) could anything have prevented the occurrence?

The knowledge dimension had three indicators: (1) was Dave/AEC aware of the potential consequences; (2) did Dave/AEC foresee the harm of injecting the patient with plutonium; (3) did Dave/AEC recognize the potential seriousness?

The third dimension, intentionality, had four indicators: (1) did Dave/AEC intend to inject the patient with plutonium; (2) could the injection have been considered an accident; (3) did Dave/AEC plan the injection in advance; (4) do you think Dave/AEC acted on his/its own will?

Finally, the fourth dimension, moral wrongfulness had three indicators: (1) was it wrong for Dave to inject the patient or was it wrong for the AEC to condone the injection; (2) was Dave acting morally when he injected the patient or was the AEC acting morally when it condoned the injection; (3) was Dave/AEC justified when he injected the patient?

\section{Results}

Multivariate analysis of variance (MANOVA) was employed, largely because all of the independent variables were dichotomous and there were multiple dependent variables. There were eight dependent variables, four for the individual actor (i.e., Dave) and four for the organizational actor (i.e., AEC). Preliminary analysis indicated that the dependent variables (i.e., the subscales) used in the analysis were significantly and positively intercorrelated (The correlation matrix is available from the author upon request). In addition, Levene's tests were run for all of the dependent variables. None were significant; therefore I am confident that the equal variances assumption was not violated. An advantage of using MANOVA rather than ANOVA is that it protects against inflated Type 1 errors due to multiple tests with correlated dependent variables [36].
TABLE 1: Items in the attribution of responsibility subscales.

\begin{tabular}{lcc}
\hline \multicolumn{2}{c}{ Alpha reliability } \\
\hline & Vignette individual & \\
Causality & & .50 \\
Knowledge & & .53 \\
Intentionality & & .58 \\
Moral wrongfulness & .65 \\
\hline & Vignette organization \\
Causality & & .55 \\
Knowledge & & .60 \\
Intentionality & & .64 \\
Moral wrongfulness & & .68 \\
\hline
\end{tabular}

Unique sums of squares were used, and the multivariate effects were based on Wilks' Lambda. Protected univariate Ftests were used to elaborate on the significant multivariate effects. Univariate effects were considered only if there was at least a trend, $P<.05$, for a given multivariate effect.

As mentioned, a general linear model MANOVA was performed on eight dependent variables: four dimensions for individual responsibility and four dimensions for organizational responsibility. Independent variables were role (autonomous or obedient), deed (cover-up or informed consent), schema (schema present or no schema present), SOP (typical or not typical), and respondent's sex (male or female). There were a total of 228 cases; however, missing data reduced the cases to 218 .

Using the Wilks' criterion, the combined dependent variables were significantly affected by role, $F(8,202)=9.64$, $P<.001$, which accounted for 28 percent of the variance. There was a significant overall multivariate effect for deed, $F(8,202)=4.80, P<.001$, which accounted for 16 percent of the variance. There was a significant overall multivariate effect for SOP, $F(8,202)=2.67, P<.01$, which accounted for 10 percent of the variance. And there was a significant multivariate effect for sex, $F(8,202)=1.97, P<.001$, which accounted for 7 percent of the variance in the multivariate model. The overall multivariate effect for schema was not significant, $F(8,202)=0.91, P>.05$. I included interaction effects for the respondent's sex because it is a betweensubjects variable and statistical power would not be significantly compromised; however, none of the interactions were significant. Specifically, I examined the interaction between sex and role, $F(8,202)=1.42, P>.05$, sex and deed, $F(8,202)=1.12, P>.05$, and sex and SOP, $F(8,202)=.33$, $P>.05$. The multivariate results are summarized in Table 2, excluding the nonsignificant interactions.

Because the multivariate effect for role was significant, I examined the univariate effects for each of the eight dependent variables. Univariate analysis indicated that when respondents received the autonomous role vignette they found the individual more responsible and the organization less responsible, on two of the dimensions, compared to respondents who received the obedient role vignette (individual causality, $F(1,209)=6.79, P<.01$, and individual intentionality, $F(1,209)=27.74, P<.001)$. The dimensions 
TABLE 2: F-statistics for multivariate effects.

\begin{tabular}{lc}
\hline Factors & Multivariate effects $^{\mathrm{a}}$ \\
\hline Role & $9.64^{* * *}$ \\
Deed & $4.80^{* * *}$ \\
SOP & $2.67^{* *}$ \\
Schema & 0.91 \\
Sex & $1.97^{*}$ \\
\hline
\end{tabular}

${ }^{*} P<.05 ;{ }^{* *} P<.01 ;{ }^{* * *} P<.001$.

${ }^{a}$ Based on Wilks' Lambda; $\mathrm{df}=$ 8, 202.

of individual knowledge and moral wrongfulness failed to reach significance.

Univariate analysis indicated that when respondents received the obedient role vignette they found the organization more responsible on each dimension than the individual, relative to respondents who received the autonomous role vignette (organizational causality, $F(1,209)=24.09, P<$ .001 , organizational knowledge, $F(1,209)=11.54, P<.01$, organizational intentionality, $F(1,209)=43.74, P<.001$, and organizational moral wrongfulness, $F(1,209)=9.92, P<$ $.01)$. The results of the univariate effects indicate that respondents who received the obedient role vignette attributed significantly more responsibility to the organization on each dimension than those who received the autonomous role vignette.

Because the multivariate effect for deed was significant I examined the univariate effects for each of the eight dependent variables. For the cover-up deed vignette, individual causality was significant, $F(1,209)=8.32, P<.01$, compared to those who received the informed consent vignette. The cover-up deed vignette also significantly affected both individual, $F(1,209)=37.14, P<.001$ and organizational moral wrongfulness, $F(1,209)=6.08, P<.01$, compared to respondents who received the informed consent vignette. The results generally support my expectations because respondents who received the cover-up vignette attributed more responsibility to the individual and less to the organization, for two of the four dimensions, than respondents who received the informed consent vignette.

The multivariate effect for schema was not significant; therefore, I will not discuss the univariate analyses for this variable.

Because the multivariate effect for SOP was significant, I examined the univariate effects for each of the dependent variables. Respondents who received the SOP typical vignette found the organization more responsible than respondents who received the SOP not typical vignette (organizational causality, $F(1,209)=12.96, P<.01$, and organizational intentionality, $F(1,209)=16.89, P<.001$, organizational morality, $F(1,209)=3.32, P<.05)$. However, respondents who received the SOP not typical vignette did not significantly differ from respondents who received the SOP typical vignette in how they attributed responsibility to the individual.

The multivariate effect for the respondent's sex was also significant; therefore, I examined the univariate effects for each of the eight dependent variables. Women attributed significantly more responsibility on three of the individual responsibility dimensions and one organizational dimension relative to men in the sample. Individual causality was significant, $F(1,209)=3.78, P<.05$, as were individual intentionality, $F(1,209)=5.37, P<.05$, individual moral wrongfulness, $F(1,209)=4.18, P<.005$, and organizational knowledge, $F(1,209)=4.82, P<.05$. Thus, the univariate analyses provide partial support for my expectations. These results are summarized in Table 3 and I expand on the meaning of these findings in the discussion below. The marginal means are reported below the $F$ values in the table.

\section{Discussion and Conclusion}

In this exploratory study I found support, or at least partial support, for the majority of the expectations based on Gailey and Lee's [1] theoretical model. Moreover, results provide further support for Hamilton's [9] "roles and deeds" model. Respondents who received a vignette in which the individual actor was in an autonomous role attributed more responsibility to the individual, on two of the four dimensions, than respondents who received the vignette in which the actor was in an obedient role. Both causality and intentionality were significant for the individual whereas knowledge and moral wrongfulness were not. I can only speculate as to why this may have been the case, but it seems that respondents did not believe that the actor had complete knowledge about what he was doing. The vignette reads, “...in order to better understand how the human body will process it" (emphasis added). If he did not have knowledge then maybe, at least according to this sample, he is also not morally wrong. This is an interesting finding and certainly warrants further examination in future research.

Respondents who received the obedient role vignette attributed more responsibility, on all four dimensions, to the organization than respondents who received the autonomous role vignette. This may indicate that respondents believe that organizations are superior to individuals. Organizations typically consist of a number of individuals with specialized skills and are organized in a rational structure; as a result, they could be presumed to possess better rationality, greater foresight, and a superior ability to anticipate the consequences of their actions than individuals [33].

For the deed condition, respondents who received the cover-up vignette attributed more responsibility to the individual, on two dimensions and to the organization on the morality dimension, than respondents who received the informed consent vignette. The significant results are interesting, if someone is covering up a deed (or action) they are both causally responsible and morally responsible, but I am unsure as to why the dimensions knowledge and intentionality failed to reach significance. One possible explanation is that it may reflect the content of the vignette and this is also a limitation of the present study. As part of a larger study, focus groups were conducted with respondents [37]. The participants in the focus groups expressed moral outrage and indignation about the human radiation experiments; as such, it is possible that the moral wrongfulness dimension outweighed their 


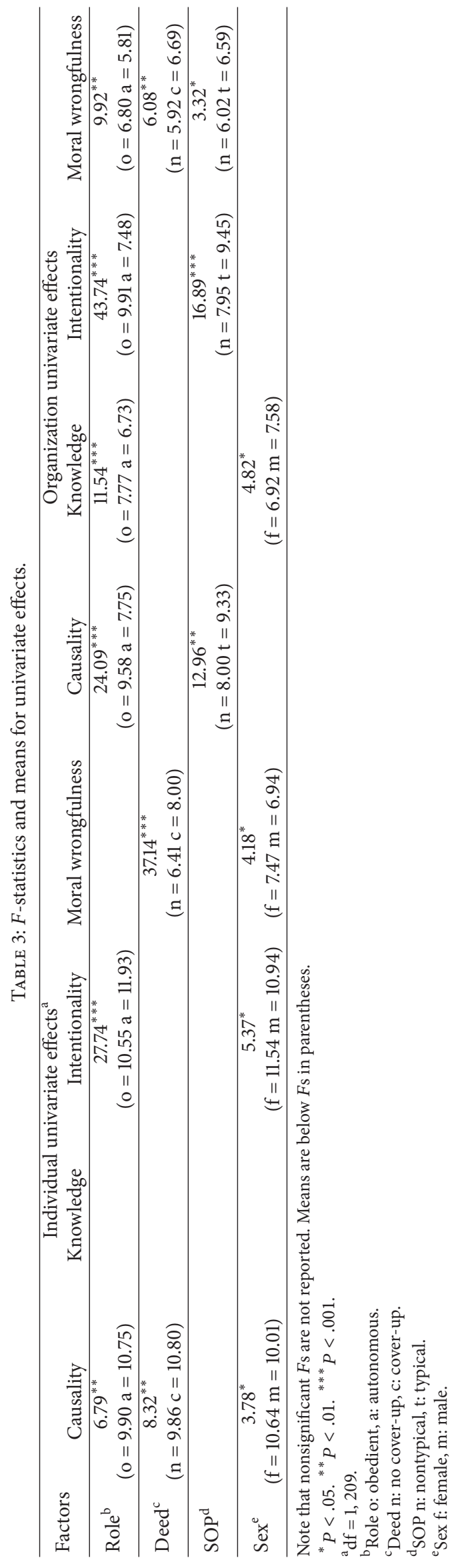


feelings of intent and knowledge. However, future research is necessary to disentangle these findings.

I found support for the inclusion of SOP; however, mental schemas failed to reach significance. Respondents who received the SOP typical vignette attributed more responsibility, on three of the dimensions to the organization, compared with respondents who received the SOP not typical vignette. These findings generally support my expectations. The fact that the knowledge dimension was not significant implies that just because organizational behaviors are standard practice does not presume that the organization had knowledge of the harm, especially if the actions were embedded in the institutional logic.

The mental schema manipulation was not significant in this study, perhaps because respondents did not think it was a legitimate rationale that the actor did not believe that what he was doing was a problem. Gailey [37] found that mental schemas were significant when the wording of the manipulation was slightly altered. Moreover, in the focus groups with participants they stressed that they thought that the AEC and Dave were merely trying to justify their actions by stating that the person was terminally ill and that that did not excuse their actions or give them the right to inject the person with plutonium. What is most interesting about the findings is that according to the Department of Energy (DOE) interviews with the actual scientists who engaged in the experiments, the scientists rationalized their behaviors by using the exact language presented in the vignette (see [38]). The scientists who actually injected people with lethal doses of plutonium stated that their actions were not a problem because the person was going to die anyway and because the experiments involved national security. The respondents in the present study apparently did not buy that rationale. Future research should improve upon this measure to determine if this aspect of institutional logic affects how perceivers attribute responsibility.

And finally, this study also indicates that men and women attribute responsibility slightly differently. Women attributed more responsibility than men to the individual, with regard to the causality, intentionality, and the moral wrongfulness dimensions. Men, compared to women, attributed significantly more knowledge to the organization, but they did not differ significantly on the other three dimensions. Previous research indicates that men and women view immoral and/or unethical behaviors differently. According to Borkowski and Ugras [32] and Landry et al. [31] men are more utilitarian than women and women tend to demonstrate stronger responses with respect to situations involving unfairness, injustice, and moral wrongfulness.

There are numerous limitations to this study. First, the findings are not generalizable because the sample consisted of undergraduates enrolled in an introductory to sociology courses at a Midwestern university. Undergraduates are a great starting point, but future research should examine these issues on a larger, more heterogeneous sample. I agree with Gailey and Falk ([4]: 674) that future research should test all five of Shaver's [3] dimensions with a representative sample.

The second limitation of the study involves the measurement of the independent variables. Manipulating the variables in the vignette is appropriate; however, interval or ratio measures of the independent variables would allow for greater precision and would facilitate the use of more sophisticated analysis, such as structural equation modeling. Future research should employ both the dichotomous measures in the vignettes and continuous measures of the independent variables in the questions following the vignette. Moreover, future researchers should utilize a large enough sample size when manipulating multiple variables within the content of the vignette to increase the confidence in the results.

The third limitation involves the manipulation of the variable mental schemas. Other research [37] has found that mental schemas do impact how respondent's attribute responsibility. As such, it seems that the actual manipulation was problematic. However, that is telling because the language came from the oral histories conducted by the DOE with the scientists who conducted the experiments (see [38]).

Finally, the fourth limitation involves the fact that this study was only a partial test of the integrated model proposed by Gailey and Lee [1]. Many aspects of the model were omitted because of time and financial constraints; however, without a test of the entire model there is no way to say with confidence which factors matter most or what matters given specific circumstances. Therefore, future research should continue to test and refine Gailey and Lee's [1] theoretical model so that a coherent understanding of how people attribute responsibility to both individuals and organizations involved in wrongdoing can be achieved. Despite these limitations, I argue that this exploratory study does provide a good first step for future research.

Future research must incorporate the above suggestions, such as utilizing a larger and representative sample, continuous measures of the independent variables to serve as manipulation checks, the inclusion of a comparison vignette, modifying only one aspect of the vignette at a time to isolate the effect of each examined dependent variable (thanks to one of the anonymous reviewers for pointing this important limitation out), and changing the manner with which mental schemas are measured, for a more methodologically robust test of the integrated model.

The results of this study point to the importance of Gailey and Lee's [1] integrated model, namely, because the findings indicate that it is important to examine the effects of sociological, psychological, and organizational factors when attempting to understand how people attribute responsibility in cases of organizational wrongdoing. Results also point to the significance of using a multidimensional measure of responsibility [3]. The multidimensional measure allows scholars to examine the whole picture of how people attribute responsibility. Because definitions of responsibility can vary by context and from person to person, it is important to allow people to specify what they are assigning, whether causal, moral, or intentional responsibility or simply the recognition that the person or organization should have known better. The multidimensional measure used in this study has provided a clearer picture of how people attribute responsibility because it allows for the examination of each of the dimensions individually. 
The present study also offers contributions to several bodies of literature. First, it adds increased support for Hamilton and colleagues' extensive research on AR over the last couple of decades. Hamilton's [9] "roles and deeds" model has not only been supported, but it has also been extended by this research. Prior to Hamilton and colleagues' research, structural and social factors were often not considered when examining how people attribute responsibility. This study reaffirms the value of including social role, which was the most powerful predictor, and contributes a new factor that is important to consider, SOP, when studying individual decision making and the attribution process.

Second, the present study has provided support for the inclusion of concepts from the organization studies literature. Until now, there has been little integration of concepts from the field of organization studies in AR research, although some attribution theorists have begun to inform research on organizations [39]. The literature on organizational wrongdoing indicates that people may view organizational misconduct differently than individual wrongdoing for a variety of reasons.

Ermann and Lundman [[40]: xvii] argue that organizational wrongdoing is not caused by "single-minded commitments to financial gain compelling the corporation to violate norms whenever rationally calculated corporate interests indicate that profit for stockholders would be increased." Organizational wrongdoing often results from interactions among complex role relations in an organization [41-43]. The present research indicates that the presence of organizational features (i.e., SOP) affects laypersons' judgments when asked to attribute responsibility for acts of wrongdoing. In other words, results indicate that organizational features influence people, consciously or not, which in turn affects how they make decisions in cases when an organization or a person in the organization is the defendant.

And finally, this research offers contributions to both social psychological and philosophical debates about responsibility. Exploring the meaning of responsibility dates back to ancient philosophy, as discussions of the concepts of responsibility began with Aristotle's theory of causes. Shaver [3] argues that it is important to understand and study philosophy to identify the dimensions of responsibility. Moral philosophy suggests which factors should be involved in judgments of responsibility, and social psychological research has identified some of the factors that influence AR. Synthesizing the two was the goal of his book where he initially introduced the multidimensional concept of responsibility. Gailey and Falk's [4] study furthered his work by providing empirical evidence that responsibility is a multidimensional concept and the present study has pointed to the importance of including a multidimensional, rather than unidimensional measure.

This manuscript offers the first empirical test, although only partial, of an integrated model outlined by Gailey and Lee [1]. Despite the limitations, the importance of testing this model is great because it can inform both scholars and policy makers of the key factors that people (often unconsciously) weigh when assigning responsibility for organizational wrongdoing. In cases of organizational wrongdoing, jurors are typically asked to determine if either, or both, the organization and individual are responsible, regardless of any contextual factors that might have influenced or allowed the wrongdoing to occur. Unfortunately, the law does not correspond well with how the average juror or layperson attributes responsibility, because jurors often consider contextual factors, often tacitly, which might decrease the likelihood of accountability. This research offers scholars a modest understanding of the factors that influence people (or potential jurors) when they are asked to attribute responsibility.

\section{Appendix}

Dave was a doctor on a research team working with the Atomic Energy Commission (AEC) to determine a safe level of exposure to radioactive plutonium for workers involved with the production of nuclear weapons. As part of this project, Dave decided [was ordered] to inject a hospital patient diagnosed as having a terminal illness with a potentially lethal dose of plutonium, in order to better understand how the human body will process it. Dave did not inform the patient of the injection in order to cover up the fact that the amount of plutonium was unsafe. [Dave did not cover up the fact that the injection was unsafe. Instead, he informed the patient and documented the injection in the patient's chart.] Dave did not believe that injecting the patient with plutonium was a problem because the patient was diagnosed as having a terminal illness and probably would not live very long anyway. [Previous sentence was omitted in half of the questionnaires.] Dave knew from past experience that using patients in this manner was typical [not typical] of AECfunded research.

\section{References}

[1] J. A. Gailey and M. T. Lee, "An integrated model of attribution of responsibility for wrongdoing in organizations," Social Psychology Quarterly, vol. 68, no. 4, pp. 338-358, 2005.

[2] F. Heider, Ed., The Psychology of Interpersonal Relations, John Wiley \& Sons, New York, NY, USA, 1958.

[3] K. G. Shaver, The Attribution of Blame. Causality, Responsibility, and Blameworthiness, Springer, New York, NY, USA, 1985.

[4] J. A. Gailey and R. F. Falk, "Attribution of responsibility a multidimensional concept," Sociological Spectrum, vol. 28, no. 6, pp. 659-680, 2008.

[5] B. Critchlow, "The blame in the bottle: attributions about drunken behavior," Personality and Social Psychology Bulletin, vol. 11, pp. 258-274, 1985.

[6] M. D. Harvey and B. G. Rule, "Moral evaluations and judgments of responsibility," Personality and Social Psychology Bulletin, vol. 4, no. 4, pp. 583-588, 1978.

[7] J. E. Krulewitz and J. E. Nash, "Effects of rape victim resistance, assault outcome, and sex of observer on attributions about rape," Journal of Personality, vol. 47, no. 4, pp. 557-574, 1979.

[8] N. Vidmar and L. D. Crinklaw, "Attributing responsibility for an accident: a methodological and conceptual critique," Canadian Journal of Behavioral Science, vol. 6, no. 2, pp. 112-130, 1974.

[9] V. L. Hamilton, "Who is responsible? Toward a social psychology of responsibility attribution," Social Psychology, vol. 41, no. 4, pp. 316-328, 1978. 
[10] V. L. Hamilton, "Intuitive psychologist or intuitive lawyer? Alternative models of the attribution process," Journal of Personality and Social Psychology, vol. 39, no. 5, pp. 767-772, 1980.

[11] V. L. Hamilton, "Chains of command: responsibility attribution in hierarchies," Journal of Applied Social Psychology, vol. 16, no. 2, pp. 118-138, 1986.

[12] V. L. Hamilton and J. Sanders, "The effect of roles and deeds on responsibility judgments: the normative structure of wrongdoing," Social Psychology Quarterly, vol. 44, no. 3, pp. 237-254, 1981.

[13] V. L. Hamilton and J. Sanders, "Universals in judging wrongdoing: Japanese and Americans compared," American Sociological Review, vol. 48, pp. 199-211, 1983.

[14] V. L. Hamilton and J. Sanders, "Crimes of obedience and conformity in the workplace: surveys of Americans, Russians, and Japanese," Journal of Social Issues, vol. 51, pp. 67-89, 1995.

[15] V. L. Hamilton and J. Sanders, "Corporate crime through citizens' eyes: stratification and responsibility in the United States, Russia, and Japan," Law and Society Review, vol. 30, no. 3, pp. 513-547, 1996.

[16] J. Sanders and V. L. Hamilton, "Is there a "common law" of responsibility? The effect of demographic variables on judgments of wrongdoing," Law and Human Behavior, vol. 11, no. 4, pp. 277-297, 1987.

[17] J. Sanders, V. L. Hamilton, G. Denisovsky et al., "Distributing responsibility for wrongdoing inside corporate hierarchies: public judgments in three societies," Law and Social Inquiry, vol. 21, no. 4, pp. 815-854, 1996.

[18] J. A. Gailey and M. T. Lee, "Influences and the assignment of responsibility for wrongdoing in organizational settings," Sociological Focus, vol. 41, no. 1, pp. 71-86, 2008.

[19] J. A. Gailey and M. T. Lee, "The impact of roles and frames on attributions of responsibility: the case of cold war human radiation experiments," Journal of Applied Social Psychology, vol. 35, no. 5, pp. 1067-1088, 2005.

[20] J. Piaget, The Moral Judgement of the Child, Harcourt, New York, NY, USA, 1932.

[21] D. L. Carper, N. J. Mietus, T. E. Shoemaker, and B. W. West, Understanding the Law, West Publishing Company, Minneapolis, Minn, USA, 1995.

[22] R. Friedland and R. Alford, "Bringing society back in: symbols, practices, and institutional contradictions," in The New Institutionalism in Organizational Analysis, W. Powell and P. DiMaggio, Eds., pp. 232-263, University of Chicago Press, Chicago, Ill, USA, 1991.

[23] R. Jackall, Moral Mazes: The World of Corporate Managers, Oxford University Press, New York, NY, USA, 1988.

[24] D. R. Simon, Elite Deviance, Allyn and Bacon, Boston, Mass, USA, 5th edition, 1996.

[25] P. DiMaggio, "Culture and cognition," Annual Review of Sociology, vol. 23, pp. 263-287, 1997.

[26] W. W. Powell and P. J. DiMaggio, The New Institutionalism in Organizational Analysis, University of Chicago Press, Chicago, Ill, USA, 1991.

[27] C. Perrow, Normal Accidents: Living with High-Risk Technologies, Basic Books, New York, NY, USA, 1984.

[28] H. Laroche, "From decision to action in organizations: decisionmaking as a social representation," Organization Science, vol. 6, no. 1, pp. 62-75, 1995.

[29] S. M. Kriesberg, "Decision making models and the control of corporate crime," Yale Law Journal, vol. 85, pp. 1091-1129, 1976.
[30] D. A. Gioia, "Pinto fires and personal ethics: a script analysis of missed opportunities," Journal of Business Ethics, vol. 11, no. 5-6, pp. 379-389, 1992.

[31] R. Landry, G. D. Moyes, and A. C. Cortes, "Ethical perceptions among Hispanic students: differences by major and gender," Journal of Education for Business, vol. 80, no. 2, pp. 102-108, 2004.

[32] S. C. Borkowski and Y. J. Ugras, "The ethical attitudes of students as a function of age, sex and experience," Journal of Business Ethics, vol. 11, no. 12, pp. 961-979, 1992.

[33] V. P. Hans and M. D. Ermann, "Responses to corporate versus individual wrongdoing," Law and Human Behavior, vol. 13, no. 2, pp. 151-166, 1989.

[34] R. McDonald, Factor Analysis and Related Methods, Lawrence Erlbaum Associates, Hillsdale, NJ, USA, 1985.

[35] L. J. Cronbach and R. J. Shavelson, "My current thoughts on coefficient alpha and successor procedures," Educational and Psychological Measurement, vol. 64, no. 3, pp. 389-390, 2004.

[36] B. G. Tabachnick and L. Fidell, Using Multivariate Statistics, Harper and Row, New York, NY, USA, 1989.

[37] J. A. Gailey, How people attribute responsibility to individuals and organizations involved in wrongdoing: an empirical assessment of an integrated model [Ph.D. dissertation], The University of Akron, Akron, Ohio, USA, 2005.

[38] Advisory Committee on Human Radiation Experiments (ACHRE), The Human Radiation Experiments: Final Report of the President's Advisory Committee, Oxford University Press, New York, NY, USA, 1996.

[39] M. J. Martinko, Attribution Theory: An Organizational Perspective, St. Lucie Press, Delray Beach, Fla, USA, 1995.

[40] M. D. Ermann and R. J. Lundman, Corporate and Governmental Deviance: Problems of Organizational Behavior in Contemporary Society, Oxford University Press, Oxford, NY, USA, 5th edition, 1996.

[41] M. T. Lee and M. D. Ermann, "Pinto "madness" as a flawed landmark narrative: an organizational and network analysis," Social Problems, vol. 46, no. 1, pp. 30-47, 1999.

[42] D. Vaughan, The Challenger Launch Decision: Risky Technology, Culture, and Deviance at NASA, University of Chicago Press, Chicago, Ill, USA, 1996.

[43] C. D. Stone, Where the Law Ends: The Social Control of Corporate Behavior, Harper and Row, New York, NY, USA, 1975. 

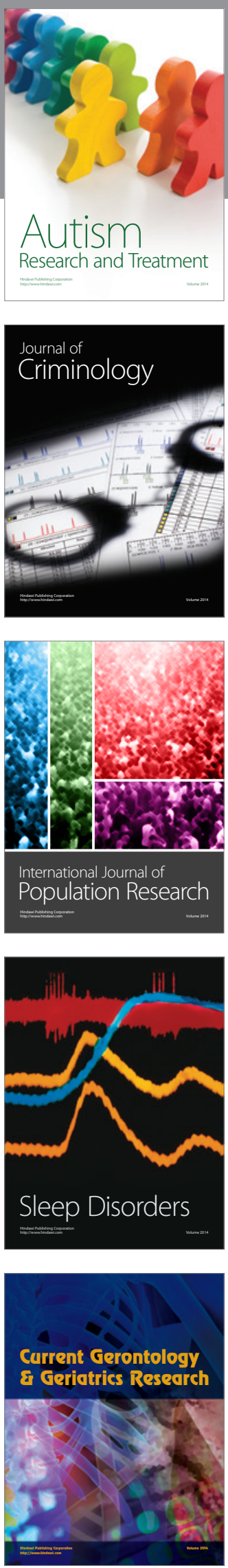
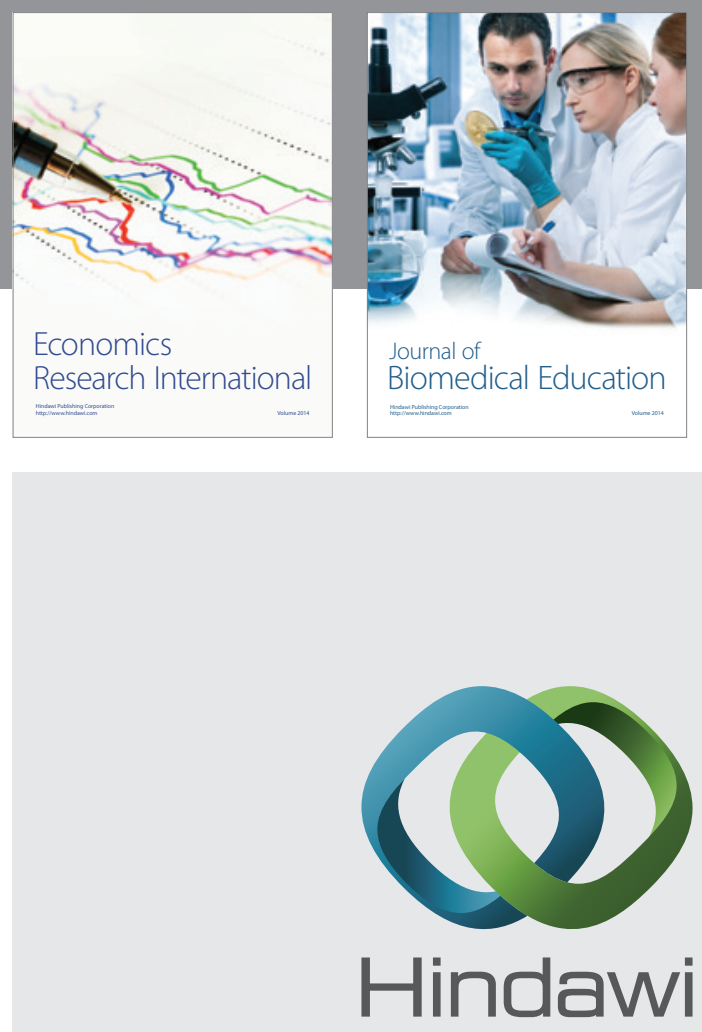

Submit your manuscripts at

http://www.hindawi.com
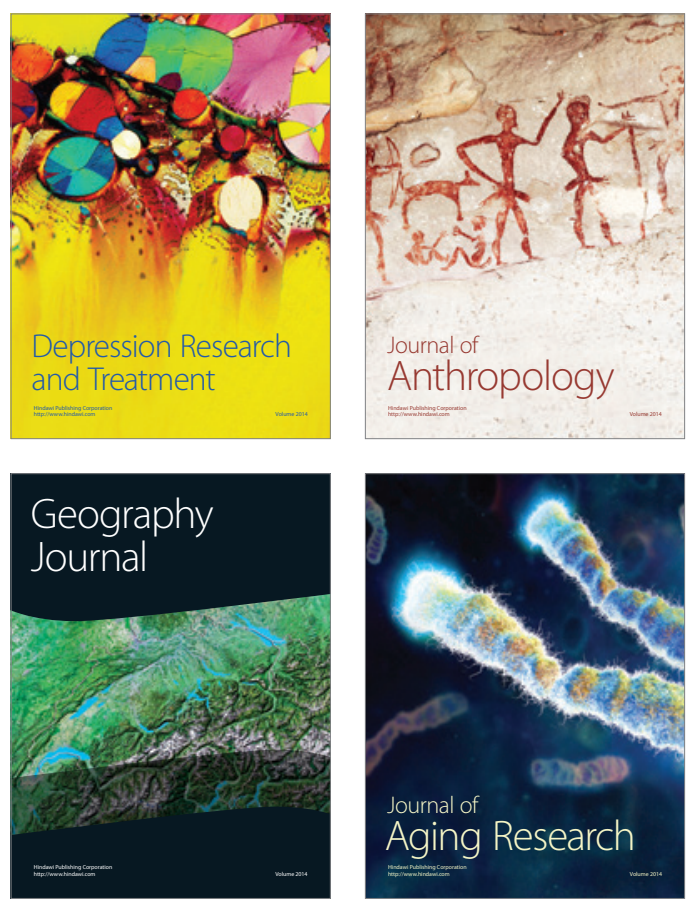
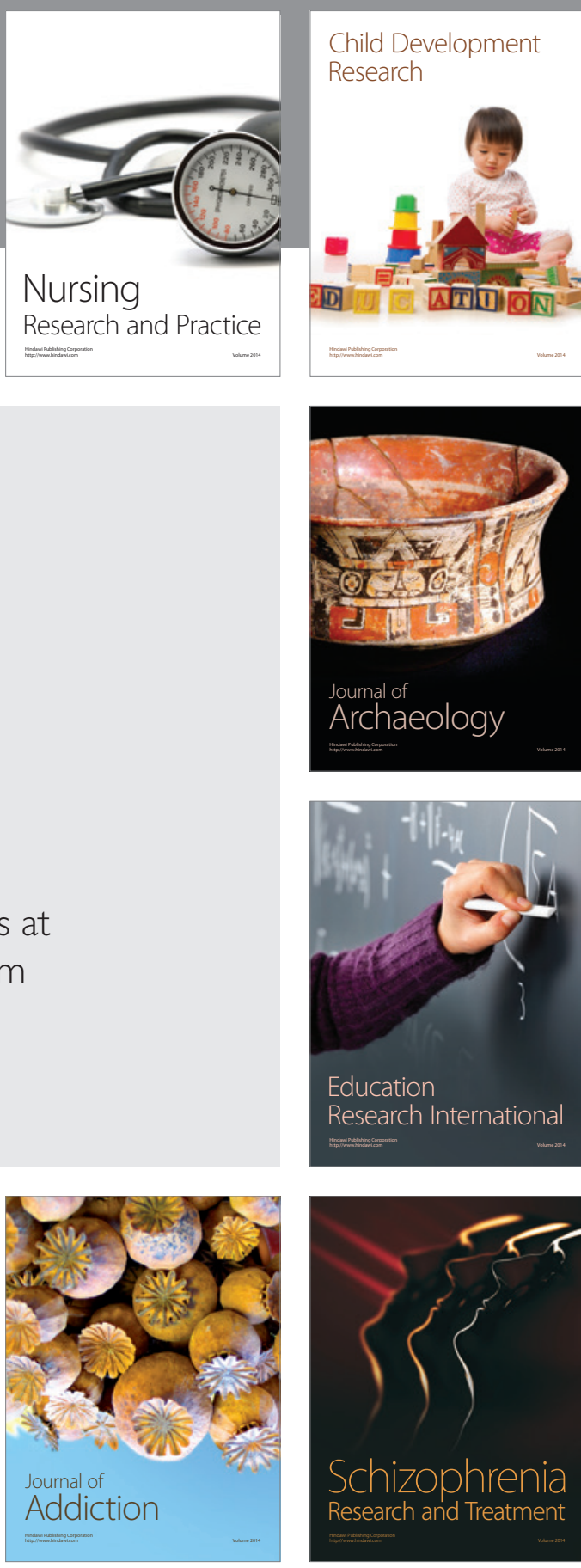

(D)
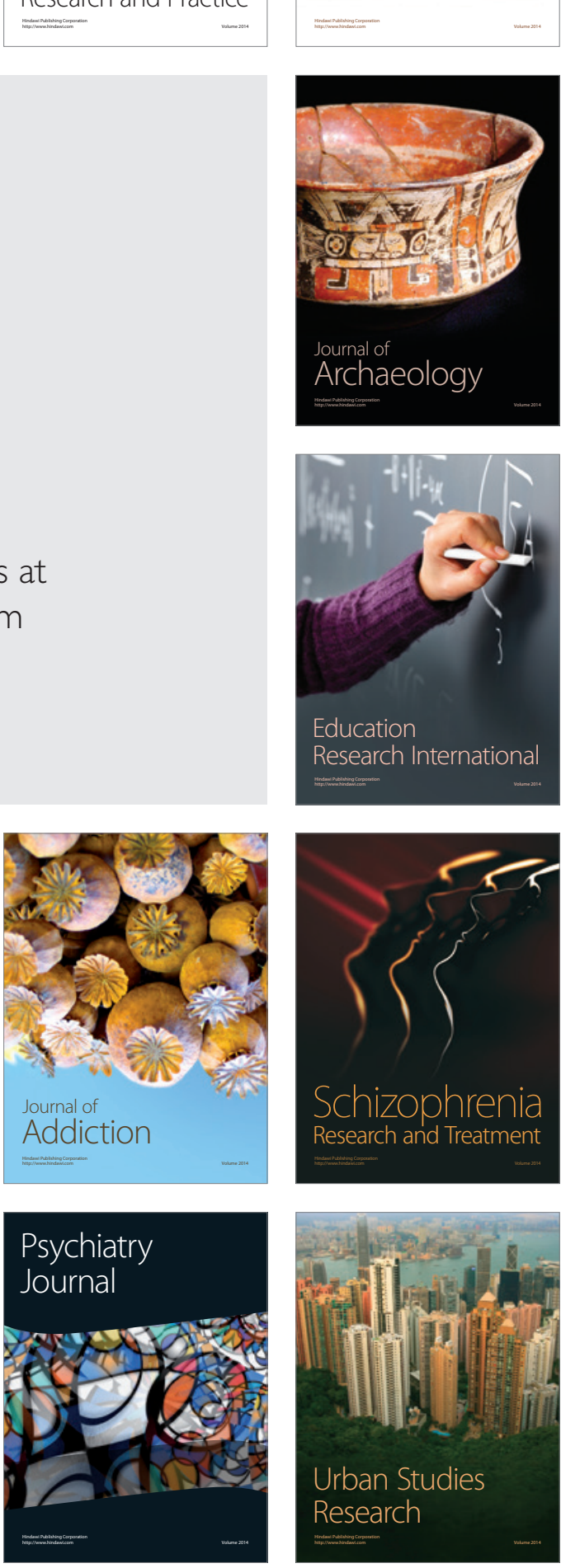